\title{
Mechanism of the reversal effect of mifepristone on drug resistance of the human cervical cancer cell line HeLa/MMC
}

\author{
H. Chen*, J. Duan* and F. Zuo \\ Department of Gynecology and Obstetrics, \\ Zhongnan Hospital of Wuhan University, Wuhan, China \\ *These authors contributed equally to this study. \\ Corresponding author: H. Chen \\ E-mail: hongchendoc@163.com
}

Genet. Mol. Res. 13 (1): 1288-1295 (2014)

Received June 25, 2013

Accepted December 17, 2013

Published February 27, 2014

DOI http://dx.doi.org/10.4238/2014.February.27.14

\begin{abstract}
We examined the ability of mifepristone to reverse the in vitro drug resistance of human cervical cancer cells resistant to mitomycin-C (HeLa/MMC) cells and investigated the mechanism of this effect. A 3-(4,5-dimethylthiazol-2-yl)-2,5-diphenyltetrazolium bromide assay was performed to detect the drug resistance of HeLa/ $\mathrm{MMC}$ cells and the reversed drug resistance in vitro. Expression levels of B-cell lymphoma 2 (Bcl-2), Bcl-2-associated X protein (Bax), and glucosylceramide synthase (GCS) were measured in HeLa and HeLa/ MMC cells. The resistance index of HeLa/MMC cells on MMC was reduced from 5.02 to 1.46 after $10 \mu \mathrm{g} / \mathrm{mL}$ mifepristone exposure. A combination of mifepristone upregulated the $\mathrm{Bax} / \mathrm{Bcl}-2$ protein expression ratio and apoptosis in $\mathrm{HeLa} / \mathrm{MMC}$ cells. GCS expression was significantly higher in HeLa/MMC cells than in HeLa cells $(\mathrm{P}<0.01)$, but distinctly declined in both cell lines after mifepristone application $(\mathrm{P}<0.01)$. Mifepristone reversed the resistance of $\mathrm{HeLa} / \mathrm{MMC}$ cells to $\mathrm{MMC}$ in vitro; the overexpression of the GCS gene and the increased expression of apoptosis-related protein Bcl-2 may play important roles
\end{abstract}


in the formation of multidrug resistance in cervical cancer.

Key words: Mifepristone; Glucosylceramide synthase gene; Multidrug resistance; Apoptosis-related protein

\section{INTRODUCTION}

Cervical cancer is the most common malignant tumor in the female genital tract and one of the most important diseases threatening the lives and health statuses of women. Since 1999, the treatment of cervical cancer has involved comprehensive treatment that combines surgery and radiotherapy with chemotherapy. Neoadjuvant chemotherapy reduces the gross tumor volume, extends the 5-year survival rate, and decreases the recurrence rate, and has thus attracted extensive attention for various studies (Hamed et al., 2012; Lai et al., 2013; Okazawa et al., 2013). However, the multidrug resistance (MDR) of tumor cells to chemotherapy influences the clinical application and efficacy of treatments.

MDR is a term used to describe the ability of drug-resistant tumors to exhibit simultaneous resistance to a number of structurally and functionally unrelated chemotherapeutic agents, and is a crucial determinant in the failure of clinical chemotherapy (Kantarjian et al., 2001). MDR shows complex mechanisms and is likely correlated with high expression of MDR-associated proteins and P-glycoprotein, a plasma membrane ATP-binding cassette transporter, as well as abnormalities in drug-metabolizing enzymes and rate-limiting enzymes in protein synthesis (Baguley, 2010). Mitomycin-C (MMC), a broad-spectrum antitumor antibiotic, has been applied in chemotherapy for gastric, colorectal, bladder, and cervical cancers; however, MDR has limited its clinical application (Zalipsky et al., 2007).

Mifepristone, as a progesterone/glucocorticoid receptor antagonist, was originally and widely used to terminate early pregnancy in clinical settings. Mifepristone was also found to increase the sensitivity of chemotherapies for gastric cancer, breast cancer, endometrial cancer, and leukemia (Gaddy et al., 2004; Li et al., 2004; Check et al., 2007; Navo et al., 2008). Its mechanisms may include: 1) blocking ceramide glycosylation and promoting cell apoptosis; 2) reducing exocytosis of MDR-associated proteins and P-glycoprotein while elevating the intracellular drug concentration; 3 ) enhancing the DNA repair capacity and changing the activity of topoisomerase II and the expression of tumor suppressor genes such as p53.

In this study, mifepristone was applied to human cervical cancer cells (HeLa) and the MMC resistant cell subline $\mathrm{HeLa} / \mathrm{MMC}$ in vitro to verify its reverse effect and conduct a preliminary investigation of its mechanisms by detecting changes in the expression of B-cell lymphoma 2 (Bcl-2) and glucosylceramide synthase (GCS).

\section{MATERIAL AND METHODS}

\section{Cell lines}

The parental HeLa and HeLa/MMC cell line were provided by the Scientific Research Center in Zhongnan Hospital of Wuhan University. HeLa and HeLa/MMC cells were cultured in RPMI-1640 medium and RPMI-1640 medium containing $6.0 \mathrm{ng} / \mathrm{mL} 18 \mathrm{nM} \mathrm{MMC}$, respectively. A stock solution of MMC (Zhejiang Hisun Pharmaceutical Co., Ltd.; Zhejiang, China) 
at a concentration of $0.4 \mathrm{mg} / \mathrm{mL}$ was prepared in RPMI-1640 medium, sterilized by filtration, and stored at $-20^{\circ} \mathrm{C}$.

\section{Reverse effect of mifepristone on drug resistance}

Crude mifepristone (a gift from Hubei Gedian Humanwell Pharmaceutical Co., Ltd.; Hubei, China) was prepared as a $0.4 \mathrm{mg} / \mathrm{mL}$ stock solution with absolute ethanol, and diluted to a working concentration with RPMI-1640 medium; the final concentration of absolute ethanol was $\leq 0.2 \%(\mathrm{v} / \mathrm{v})$. This solution was filter-sterilized.

$\mathrm{HeLa}$ and $\mathrm{HeLa} / \mathrm{MMC}$ cells in logarithmic phase were seeded on a 96-well plate with $2 \times 10^{4}$ cells in each well, and were cultured at $37^{\circ} \mathrm{C}$ for $24 \mathrm{~h}$. Different MMC and/or mifepristone concentrations were incubated with the cells in RPMI-1640 medium containing 5\% fetal bovine serum for $72 \mathrm{~h}$.

The drug treatment scheme included the following: 1) MMC group (0.00625, 0.0125, $0.025,0.05$, and $0.1 \mu \mathrm{g} / \mathrm{mL}$ ); 2) mifepristone group (10 and $20 \mu \mathrm{g} / \mathrm{mL}$ ); 3) MMC plus mifepristone group; 4) control group with equal amounts culture medium; 5) blank group. Each group was replicated in 3 wells at a final volume of $200 \mu \mathrm{L}$. The culture medium was removed after $72 \mathrm{~h}$, and $10 \mu \mathrm{L}$ 3-(4,5-dimethylthiazol-2-yl)-2,5-diphenyltetrazolium bromide solution was added to each well (Wuhan Cyber Biological Products Co., Ltd., Wuhan, China). After 4 $\mathrm{h}$ of incubation, $100 \mu \mathrm{L}$ dimethylsulfoxide was added and the mixture was oscillated until all of the crystals had been dissolved. An enzyme-linked immunosorbent assay reader was used to detect optical density (OD) values at $490 \mathrm{~nm}$ for each well. The cell proliferation inhibition rate was calculated as follows: inhibition rate $=(1-$ OD value in the test group / OD value in the control group) $\times 100 \%$. The half maximal inhibitory concentration $\left(\mathrm{IC}_{50}\right)$ was calculated from the dose-response curve. The resistance index (RI) was calculated according to the following formula: $\mathrm{RI}=\mathrm{IC}_{50 \mathrm{a}} / \mathrm{IC}_{50 \mathrm{~b}}(\mathrm{a}=\mathrm{HeLa} / \mathrm{MMC}$ cells, $\mathrm{b}=$ HeLa cells $)$.

\section{Immunohistochemistry (IHC)}

HeLa and HeLa/MMC cells were seeded on 6-well plates with $2 \times 10^{4}$ cells in each 1-mL well. The drug treatment scheme was as follows: 1) blank group; 2) $10 \mu \mathrm{g} / \mathrm{mL}$ mifepristone group; 3) $0.00625 \mu \mathrm{g} / \mathrm{mL}$ MMC group; 4) MMC plus mifepristone group. Each group was replicated in 2 wells with two 1-cm disinfected cover glass pieces in each well. The culture medium was removed after $72 \mathrm{~h}$, followed by glass washing, fixation, serum blocking, and incubation with Bax and Bcl-2 primary antibodies (Wuhan Cyber Biological Products Co., Ltd.) and goat anti-mouse IgG secondary antibodies. The glass was washed with phosphate-buffered saline and incubated with streptavidin-biotin complex, followed by incubation with diaminobenzidine color development; hematoxylin counterstaining and mounting were performed before observation.

\section{Reverse transcription polymerase chain reaction (RT-PCR)}

Mifepristone and/or MMC were respectively applied to HeLa and HeLa/MMC cells in logarithmic phase for $48 \mathrm{~h}$, and the drug treatment scheme was the same as that used in the IHC experiment. Total RNA from cultured cells was extracted using the TRIzoL method (Invitrogen; 
Carlsbad, CA, USA) and RNA purity was analyzed using an ultraviolet spectrophotometer.

The Primer 5.0 software was used to design primers based on the gene sequences of GCS and $\beta$-actin, which were synthesized by Shanghai Sangon Biological Engineering Co., Ltd. (Shanghai, China). The sequence of the GCS gene forward primer was 5'-GATACGCTTACTGACATGGTGA-3'; the sequence of the GCS reverse primer was 5'-GAAACCAGTTACATTGGCAGAG-3'; the size of the GCS gene products was $162 \mathrm{bp}$. The sequence of the $\beta$-actin forward primer was 5'-AGCGAGCATCCCCCAAAGTT-3'; the sequence of the $\beta$-actin reverse primer was 5'-GGGCACGAAGGCTCATCATT-3'; the size of the $\beta$-actin gene product was $284 \mathrm{bp}$. A One-step RT-PCR Kit (Fermentas; Vilnius, Lithuania) was used to amplify the $G C S$ and $\beta$-actin genes. The procedure for amplification of cDNA included 28 cycles, each of which was as follows: $90^{\circ} \mathrm{C}$ for $30 \mathrm{~s} \rightarrow G C S 50^{\circ} \mathrm{C} / \beta$-actin $54^{\circ} \mathrm{C}$ for $30 \mathrm{~s} \rightarrow 72^{\circ} \mathrm{C}$ for $25 \mathrm{~s}$. Products were visualized by $1.5 \%$ agarose gel electrophoresis with constant voltage, and images were acquired and analyzed using a gel imaging analysis system.

\section{Statistical analysis}

Data reported as means $\pm \mathrm{SE}$, and multiple groups in the same cell lines were compared using one-way analysis of variance; the Student $t$-test was utilized to compare groups with the same treatment in different cell lines and the group combined with mifepristone in the same cell lines before and after medication. $\mathrm{P}<0.05$ was considered to be significant.

\section{RESULTS}

\section{Mifepristone reversed drug resistance}

Figure 1 shows that the survival rate of the 2 cell lines was reduced with increasing MMC concentration, and that the survival rate of $\mathrm{HeLa} / \mathrm{MMC}$ cells was higher than that of HeLa cells at all MMC concentrations $(\mathrm{P}<0.01)$. The growth inhibitory effects of 20 and $10 \mu \mathrm{g} / \mathrm{mL}$ mifepristone were 8.67 and $1.55 \%$ for HeLa/MMC cells and 33.69 and $6.18 \%$ for $\mathrm{HeLa}$ cells, respectively. In the subsequent experiment that reversed drug resistance of HeLa/ MMC, treatment of mifepristone alone at low concentration $(10 \mu \mathrm{g} / \mathrm{mL})$ was selected as a drug treatment factor owing to its low cell growth inhibitory effect.
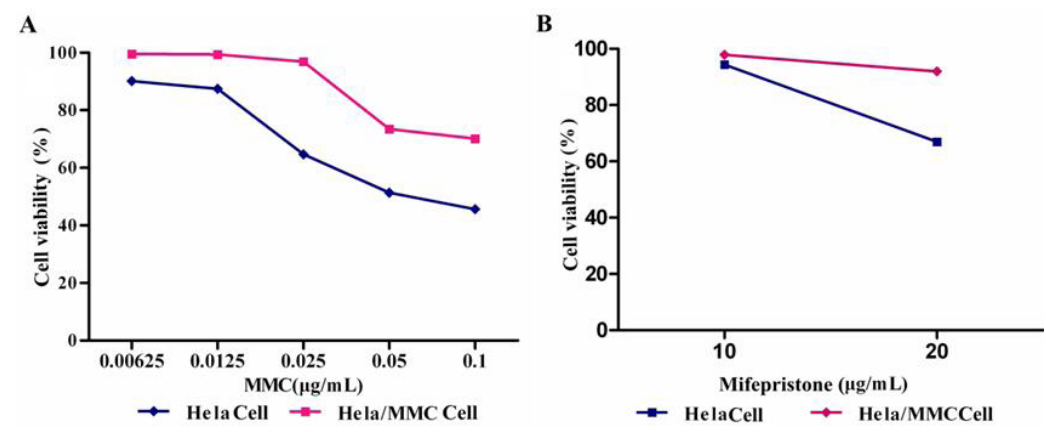

Figure 1. Cell growth inhibitory effects of MMC and mifepristone on HeLa and HeLa/MMC cells. A. Cell growth inhibitory effect of MMC; B. cell growth inhibitory effect of mifepristone. 
Table 1 shows that the $\mathrm{IC}_{50}$ values of $\mathrm{HeLa} / \mathrm{MMC}$ and HeLa cells with MMC were 0.324 $\mu \mathrm{g} / \mathrm{mL}$ and $0.064 \mu \mathrm{g} / \mathrm{mL}$, respectively, and the RI of HeLa/MMC cells against MMC was 5.02. The RI of HeLa/MMC cells was reduced to 1.46 after treatment with mifepristone. Drug resistance of HeLa/MMC cells markedly reversed after application of $0.00625 \mu \mathrm{g} / \mathrm{mL}$ MMC with mifepristone. Therefore, subsequent experiments used $0.00625 \mu \mathrm{g} / \mathrm{mL} \mathrm{MMC}$ as a processing factor.

Table 1. $\mathrm{IC}_{50}$ of HeLa and HeLa/MMC cells before and after combined application of $10 \mu \mathrm{g} / \mathrm{mL}$ mifepristone
$(\mathrm{N}=4$, means $\pm \mathrm{SE})$.
\begin{tabular}{lcc} 
& \\
\hline Cell line & $\mathrm{MMC}(\mu \mathrm{g} / \mathrm{mL})$ & MMC with mifepristone $(\mu \mathrm{g} / \mathrm{mL})$ \\
\hline HeLa/MMC & $0.324 \pm 0.002$ & $0.095 \pm 0.001^{* *}$ \\
HeLa & $0.064 \pm 0.001$ & $0.063 \pm 0.002$ \\
\hline
\end{tabular}

In the HeLa/MMC cell line, cell viability was significantly inhibited in the combination group compared with the MMC group, $* * \mathrm{P}<0.01$.

\section{Bcl-2 and Bax expression}

Tables 2 and 3 show that Bax protein expression was higher and Bcl-2 protein expression was lower in HeLa cells than in HeLa/MMC cells for both the control and MMC groups (P $<0.05)$. After combination treatment with mifepristone, HeLa/MMC cells expressed increased amounts of Bax protein and decreased amounts of Bcl-2; the ratio of Bax/Bcl-2 was elevated, indicating that a combination of $\mathrm{MMC}$ and mifepristone treatment enhanced cellular Bax expression and the Bax/Bcl-2 ratio, thereby reversing drug resistance and promoting cell apoptosis.

\begin{tabular}{lcc}
\multicolumn{1}{c}{ Table 2. Expression of Bax protein in HeLa and HeLa/MMC cells from each group (N $=5$, means $\pm \mathrm{SE})}$. \\
\hline Group & HeLa (OD value) & HeLa/MMC (OD value) \\
\hline Control group & $0.31 \pm 0.01$ & $0.28 \pm 0.03^{*}$ \\
MMC group & $0.41 \pm 0.04$ & $0.34 \pm 0.03^{*}$ \\
Mifepristone group & $0.36 \pm 0.03$ & $0.32 \pm 0.01$ \\
Combination group & $0.55 \pm 0.02$ & $0.57 \pm 0.01$ \\
\hline
\end{tabular}

Compared with the HeLa cell line, expression of Bax protein was lower in the HeLa/MMC cell line in the control and MMC groups, $* \mathrm{P}<0.05$. In the HeLa/MMC cell line, compared with the MMC group, the expression of Bax was significantly increased, ${ }^{\mathbf{P}}<0.05$.

Table 3. Expression of Bcl-2 protein in HeLa and HeLa/MMC cells from each group $(\mathrm{N}=5$, means $\pm \mathrm{SE})$.

\begin{tabular}{lcc}
\hline Group & HeLa (OD value) & HeLa/MMC (OD value) \\
\hline Control group & $0.33 \pm 0.01$ & $0.38 \pm 0.02 *$ \\
MMC group & $0.28 \pm 0.03$ & $0.33 \pm 0.01 *$ \\
Mifepristone group & $0.35 \pm 0.01$ & $0.38 \pm 0.01$ \\
Combination group & $0.25 \pm 0.02$ & $0.27 \pm 0.01 \star$ \\
\hline Compared
\end{tabular}

Compared with HeLa cells, expression of Bcl-2 was higher in the HeLa/MMC cell line for the control and MMC groups, ${ }^{*} \mathrm{P}<0.05$. In the HeLa/MMC cell line, combination use of mifepristone and MMC inhibited expression of Bcl-2 compared with the MMC group, ${ }^{\mathbf{A}} \mathrm{P}<0.05$.

\section{GCS expression}

As shown in Figure 2 and Table 4, GCS expression was significantly higher in HeLa/ 
MMC cells than in HeLa cells in both the control and MMC groups $(\mathrm{P}<0.01)$; only mifepristone showed no obvious effect on GCS expression in the 2 cell lines $(\mathrm{P}>0.05)$; individual application of MMC upregulated GCS expression by 1.55 times compared with that of the control group in the HeLa/MMC cell line $(\mathrm{P}<0.01)$; a combination of MMC and mifepristone treatment distinctly reduced GCS expression in both cell lines $(\mathrm{P}<0.01)$. These results indicate that combination treatment with MMC and mifepristone dramatically inhibited GCS expression in parental and resistant cell lines and may affect MMC function.

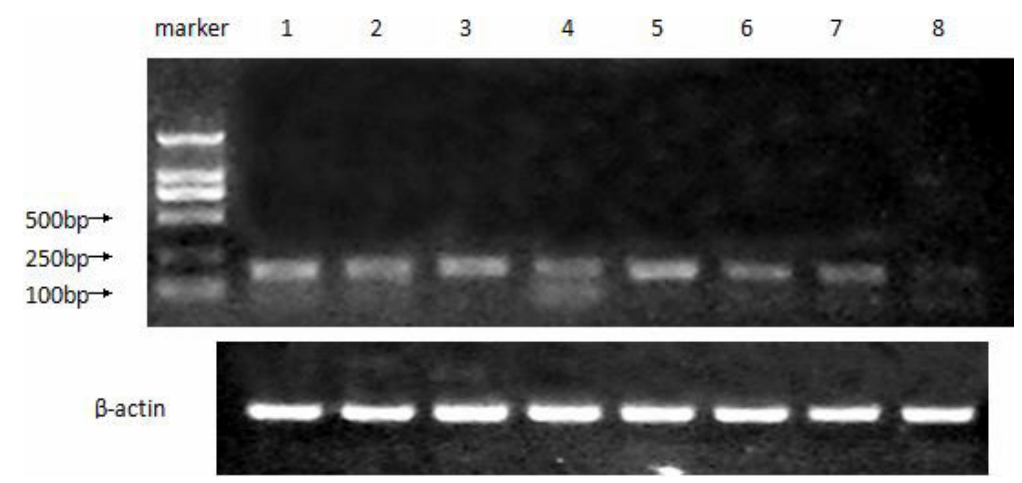

Figure 2. Expression of GCS in HeLa and HeLa/MMC cells and the effects of mifepristone and MMC on GCS expression. Lane $1=\mathrm{HeLa} / \mathrm{MMC}$, control group; lane $2=\mathrm{HeLa}$, control group; lane $3=\mathrm{HeLa} / \mathrm{MMC}$, mifepristone group; lane $4=\mathrm{HeLa}$, mifepristone group; lane $5=\mathrm{HeLa} / \mathrm{MMC}, \mathrm{MMC}$ group; lane $6=\mathrm{HeLa}$, MMC group; lane $7=\mathrm{HeLa} / \mathrm{MMC}$, combination group; lane $8=\mathrm{HeLa}$, combination group.

Table 4. Semi-quantitative RT-PCR results of GCS expression in HeLa and HeLa/MMC cells of each group $(\mathrm{N}=4$, means $\pm \mathrm{SE})$.

\begin{tabular}{lcccr}
\hline Cell line & Control group & Mifepristone group & MMC group & Combination group \\
\hline HeLa/MMC & $0.36 \pm 0.04^{* *}$ & $0.32 \pm 0.07^{*}$ & $0.54 \pm 0.1^{* * / *}$ & $0.24 \pm 0.02^{* * *}$ \\
HeLa & $0.24 \pm 0.03$ & $0.21 \pm 0.03$ & $0.16 \pm 0.01$ & $0.04 \pm 0.01^{*}$ \\
\hline
\end{tabular}

Compared with the HeLa cell line, GCS expression was increased in the HeLa/MMC cell line, $* \mathrm{P}<0.05$, **P $<$ 0.01. GCS expression was significantly inhibited in the combination treatment group in both cell lines compared with other groups, MMC stimulated GCS expression in the HeLa/MMC cell line, ${ }^{, P}<0.01$.

\section{DISCUSSION}

Mifepristone selectively inhibits the formation and development of many tumor types and plays an anti-tumor role as an antagonist through progesterone and glucocorticoid receptors (Kacinski et al., 2001; Luo et al., 2009; Ligr et al., 2012). In this study, $10 \mu \mathrm{g} / \mathrm{mL}$ mifepristone and MMC treatment at different concentrations was applied to $\mathrm{HeLa} / \mathrm{MMC}$ cells; mifepristone alone had no significant inhibitory effect on the development of HeLa/MMC cells, but both the inhibition rate and drug sensitivity of the cells increased after combination treatment with $\mathrm{MMC}$, indicating that other than anti-tumor activity, mifepristone reverses the drug resistance of tumor cells to some extent. It has been reported that mifepristone can also reverse the drug resistance of tumor cell lines from lung cancer, breast cancer, thymic tumors, ovarian cancer, prostate cancer, stomach cancer, and leukemia, among others, which confirms 
its role as a resistance modifier in reversing the drug resistance of tumor cells (Payen et al., 1999; Check et al., 2010).

The genes encoding Bcl-2 and Bax regulate cell apoptosis, and Bcl-2 protein encoded by the $B c l-2$ gene resists cell apoptosis; Bax shows the opposite effect, which is to promote apoptosis. According to previous studies, overexpression of the $\mathrm{Bcl}-2$ gene and related proteins is important in tumorigenesis and multiple drug resistance. Schneider et al. (1998) found that mifepristone inhibits the growth of KLE cells and endometrial cancer cells, as well as reduces the expression of the Bax gene. In this study, mifepristone was found to enhance Bax protein expression and reduce Bcl-2 protein expression in HeLa/MMC cells after combination treatment of MMC with mifepristone. This treatment inhibited the proliferation of drug-resistant cervical cancer cells and promoted cell apoptosis. A sensitization effect of mifepristone on renal carcinoma Caki cells to TRAIL-induced apoptosis was found by Min et al. (2012). This effect was independent of mifepristone's antiglucocorticoid and antiprogesterone roles, and one of these roles downregulated Bcl-2.

Lucci et al. (1999) reported that mifepristone could block ceramide glycosylation, reversing the resistance of the human breast cancer cell MCF-7-AdrR to adriamycin. A series of studies showed that mifepristone reverses the resistance of human breast cancer MCF-7-AdrR cells to doxorubicin and the resistance of COC (1)/DDP cells to cisplatin (Hu et al., 2008; Liu and Wang, 2008). In this study, we found that mifepristone alone could not significantly affect the expression of GCS in HeLa cells and HeLa/MMC cells $(\mathrm{P}>0.05)$, but combination of mifepristone and MMC treatment significantly reduced the GCS expression level $(\mathrm{P}<$ 0.01 ) while cell sensitivity to MMC increased. We hypothesized that the inhibitory effect of mifepristone on GCS expression in HeLa/MMC cells required the co-existence of MMC, and that this combination reversed the drug resistance to MMC by inhibiting GCS expression. This also supported our hypothesis that the mifepristone effect was independent of its antiprogesterone role and directly influenced the MDR mechanism.

Ceramide was negatively correlated with Bcl-2 expression, indicating that a reduction in ceramide results in upregulation of $B c l-2$ expression, whereas GCS decreases the amount of ceramide through ceramide glycosylation, influencing the signaling pathways of cell apoptosis/anti-apoptosis and causing drug resistance. Mifepristone induces cell apoptosis by downregulating Bcl-2 expression and elevating transforming growth factor-beta 1 (TGFB1) expression in LNCaP cells (a prostate cancer cell line) (Check et al., 2010). Silencing of the GCS gene in human ovarian cancer cells enhances the sensitivity of p53 mutant cells to doxorubicin and induces the expression of p53-responsive genes, including Bax (Liu et al., 2011). In our study, HeLa/MMC cells overexpressed GCS and enhanced Bcl-2 protein expression. Combination treatment with mifepristone and MMC markedly inhibited GCS expression and simultaneously reduced Bcl-2 protein expression in HeLa/MMC cells, indicating that mifepristone regulated the expression of $B c l-2$ and Bax as well as GCS. This data is in agreement with another study conducted by Zhang et al. (2012), who found that doxorubicin significantly upregulated the expression of GCS in estrogen receptor alpha (ER $\alpha)$-positive MCF-7 cells. When the Sp1 site of the GCS promoter or ER $\alpha$ was inhibited, this upregulation of $G C S$ by doxorubicin was also inhibited. The cascade sequence on the HeLa/MMC cells by mifepristone requires further investigation.

In conclusion, GCS overexpression, enhanced Bcl-2 protein expression, and decreased Bax protein expression may play crucial roles in the development of MDR in cervical cancer 
cells. Mifepristone can reverse the drug resistance of HeLa/MMC cells in vitro, which is likely associated with downregulation of $B c l-2$ expression and inhibition of $G C S$ expression. However, the detailed cascade correlation was not evaluated in this study and should be further examined.

\section{REFERENCES}

Baguley BC (2010). Multiple drug resistance mechanisms in cancer. Mol. Biotechnol. 46: 308-316.

Check JH, Sansoucie L, Chern J, Amadi N, et al. (2007). Evidence that progesterone receptor antagonists may help in the treatment of a variety of cancers by locally suppressing natural killer cell activity. Clin. Exp. Obstet. Gynecol. 34: 207-211.

Check JH, Dix E, Wilson C and Check D (2010). Progesterone receptor antagonist therapy has therapeutic potential even in cancer restricted to males as evidenced from murine testicular and prostate cancer studies. Anticancer Res. 30: 4921-4923.

Gaddy VT, Barrett JT, Delk JN, Kallab AM, et al. (2004). Mifepristone induces growth arrest, caspase activation, and apoptosis of estrogen receptor-expressing, antiestrogen-resistant breast cancer cells. Clin. Cancer Res. 10: 52155225 .

Hamed AH, Shepard MK, Maglinte DD, Ding S, et al. (2012). Neoadjuvant chemotherapy followed by simultaneous robotic radical trachelectomy and reversal of tubal sterilization in stage IB2 cervical cancer. JSLS 16: 650-653.

Hu P, Chen T, Tian B, Luo G, et al. (2008). Expression of GCS gene in human doxorubicin-resistant MCF-7/ADR cells and its significance. China Oncol. 18: 267-270.

Kacinski BM, Flick MB and Sapi E (2001). RU-486 can abolish glucocorticoid-induced increases in CSF-1 receptor expression in primary human breast carcinoma specimens. J. Soc. Gynecol. Investig. 8: 114-116.

Kantarjian HM, Talpaz M, Santini V, Murgo A, et al. (2001). Homoharringtonine: history, current research, and future direction. Cancer 92: 1591-1605.

Lai JC, Chou YJ, Huang N, Tsai JJ, et al. (2013). Survival analysis of Stage IIA1 and IIA2 cervical cancer patients. Taiwan J. Obstet. Gynecol. 52: 33-38.

Li DQ, Wang ZB, Bai J, Zhao J, et al. (2004). Reversal of multidrug resistance in drug-resistant human gastric cancer cell line SGC7901/VCR by antiprogestin drug mifepristone. World J. Gastroenterol. 10: 1722-1725.

Ligr M, Li Y, Logan SK, Taneja S, et al. (2012). Mifepristone inhibits GRbeta coupled prostate cancer cell proliferation. J. Urol. 188: 981-988.

Liu Y and Wang LL (2008). Mifepristone modulates glucosylceramide synthase expression and reverse multidrug resistance in ovarian cancer cells. Nan. Fang Yi Ke Da Xue Xue Bao 28: 1727-1730.

Liu YY, Patwardhan GA, Bhinge K, Gupta V, et al. (2011). Suppression of glucosylceramide synthase restores p53dependent apoptosis in mutant p53 cancer cells. Cancer Res. 71: 2276-2285.

Lucci A, Giuliano AE, Han TY, Dinur T, et al. (1999). Ceramide toxicity and metabolism differ in wild-type and multidrugresistant cancer cells. Int. J. Oncol. 15: 535-540.

Luo X, Yin P, Reierstad S, Ishikawa H, et al. (2009). Progesterone and mifepristone regulate L-type amino acid transporter 2 and 4F2 heavy chain expression in uterine leiomyoma cells. J. Clin. Endocrinol. Metab. 94: 4533-4539.

Min KJ, Jang JH, Lee JT, Choi KS, et al. (2012). Glucocorticoid receptor antagonist sensitizes TRAIL-induced apoptosis in renal carcinoma cells through up-regulation of DR5 and down-regulation of c-FLIP(L) and Bcl-2. J. Mol. Med. 90: 309-319.

Navo MA, Smith JA, Gaikwad A, Burke T, et al. (2008). In vitro evaluation of the growth inhibition and apoptosis effect of mifepristone (RU486) in human Ishikawa and HEC1A endometrial cancer cell lines. Cancer Chemother. Pharmacol. 62: 483-489.

Okazawa M, Mabuchi S, Isohashi F, Suzuki O, et al. (2013). Impact of the addition of concurrent chemotherapy to pelvic radiotherapy in surgically treated stage IB1-IIB cervical cancer patients with intermediate-risk or high-risk factors: a 13-year experience. Int. J. Gynecol. Cancer 23: 567-575.

Payen L, Delugin L, Courtois A, Trinquart Y, et al. (1999). Reversal of MRP-mediated multidrug resistance in human lung cancer cells by the antiprogestatin drug RU486. Biochem. Biophys. Res. Commun. 258: 513-518.

Schneider CC, Gibb RK, Taylor DD, Wan T, et al. (1998). Inhibition of endometrial cancer cell lines by mifepristone (RU 486). J. Soc. Gynecol. Investig. 5: 334-338.

Zalipsky S, Saad M, Kiwan R, Ber E, et al. (2007). Antitumor activity of new liposomal prodrug of mitomycin C in multidrug resistant solid tumor: insights of the mechanism of action. J. Drug Target 15: 518-530.

Zhang X, Wu X, Su P, Gao Y, et al. (2012). Doxorubicin influences the expression of glucosylceramide synthase in invasive ductal breast cancer. PLoS One 7: e48492. 